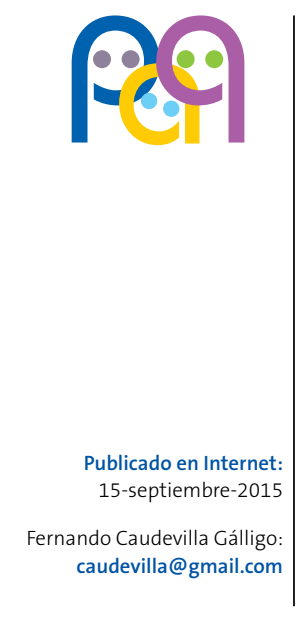

Editorial

\section{Pedro, el Lobo y las drogas de verano}

F. Caudevilla Gálligo

Médico de Familia. CS Puerta Bonita, Madrid. España. Experto Universitario en Drogodependencias. Miembro del Grupo de Intervención en Drogas de la Sociedad Española de Medicina Familiar

y Comunitaria.
El paréntesis en el ritmo cotidiano que suponen las vacaciones estivales hace que esta sea una época en la que las noticias relevantes escasean. Pero los medios de comunicación necesitan mantener la atención del lector o el televidente. Drogas y adolescentes son una combinación atractiva en este sentido y desde hace unos años todos los veranos aparecen noticias sobre "nuevas drogas". Partiendo de datos anecdóticos, sesgados o directamente fruto de las suposiciones de los periodistas (y algunos profesionales con escasos conocimientos sobre el tema) todos los años se crean serpientes de verano sobre supuestas "nuevas drogas de moda" que están basadas en información errónea, incorrecta o exagerada.

Este 2015, un caso de intoxicación ocasional con $\alpha$-pirrolidinopentiofenona ( $\alpha$-PVP), conocida en argot como flakka, bastó para que la prensa la bautizara como "la nueva droga de moda". La $\alpha$-PVP es una catinona estimulante que lleva detectándose esporádicamente desde el año 2011 en España y no existen datos que indiquen que su disponibilidad, su prevalencia de uso o el número de intoxicaciones se haya incrementado ${ }^{1}$. Sin ningún dato objetivo que lo avale, la prensa se ha empeñado en presentar un fenómeno esporádico como si fuera un problema prevalente entre los jóvenes.

El culebrón veraniego del 2013 tuvo más impacto mediático: la metilendioxipirovalerona (MDPV) fue bautizada como "droga caníbal" por la prensa a raíz de dos supuestos casos en Ibiza, sobre los que nunca existió confirmación toxicológica. Corrieron ríos de tinta sobre episodios de agresividad y canibalismo que producían las "sales de baño" (presentación habitual de este tipo de sustancias) ${ }^{1,2}$, pese a que no existía ningún dato científico que confirmara este extremo. Dio igual que la noticia estuviera basada en hechos falsos ${ }^{3}$, como también sucedió en el supuesto uso de tampones impregnados en vodka como nueva forma de emborracharse entre los jóvenes que habíamos leído un año antes $^{4}$. En todos los casos las sustancias emergentes se presentan como fenómenos epidémicos, aunque su presencia en el mercado de drogas es por suerte esporádica ${ }^{1,2}$. También se asocia su consumo a los adolescentes, aunque los datos más recientes

Cómo citar este artículo: Caudevilla Gálligo F. Pedro, el Lobo y las drogas de verano. Rev Pediatr Aten Primaria. 2015;17:203-4. 
del Plan Nacional sobre Drogas nos señalan que su consumo ocasional en población escolar es menor del $0,4 \%^{5}$. Pero todo da lo mismo: sobre todo en verano y en relación con las drogas, no hay que dejar que la realidad estropee una buena noticia.

Existen muchos aspectos relevantes en los que el pediatra de Atención Primaria puede intervenir en relación con las drogas. Los problemas de tiempo y de falta de formación específica son las limitaciones más importantes. En relación con el tiempo, existen modelos de intervención breve para poder explorar y valorar el consumo y aconsejar a jóvenes y padres. Con respecto a la formación, es importante que esta tenga la misma calidad que se exige

\section{BIBLIOGRAFÍA}

1. Caudevilla Gálligo F, Ventura M, Indave Ruiz BI, Fornís I. Presence and composition of cathinone derivatives in drug taken from a Drug Test Service in Spain (2010-2012). Hum Psychopharmacol Clin Exp. 2013 28:341-4

2. Fornís Espinosa I, Vidal Giné C, Caudevilla Gálligo F, Ventura Vilamala M. Nuevas drogas de síntesis en España: legal highs (2010-2012). Med Clin (Barc). 2013;140:189-90.

3. La droga caníbal: ¿realidad o ciencia ficción? Nota de prensa, 2014. En: Energy Control, Asociación Bienestar y Desarrollo [en línea] [consultado el 15/09/2015]. Disponible en http://energycontrol. org/noticias/539-comunicado-de-prensa-la-drogacanibal-irealidad-o-ciencia-ficcion.html otros ámbitos. Aconsejar sobre vacunas o alimentación basándose en un magazine matinal o un suplemento de prensa sería considerado como algo grotesco o reprobable. Pero en relación con las drogas, con demasiada frecuencia se sustituye la falta de formación reglada por las historias fantasiosas con las que asustan los medios de comunicación. A la hora de abordar al adolescente es imprescindible que la información que transmitamos sea coherente con su propia experiencia, la de su grupo de iguales y con la realidad. De otra forma, como en el cuento de "Pedro y el Lobo", existe un riesgo de pérdida de credibilidad y que cuando de verdad "viene el lobo" sea demasiado tarde.

4. El tampodka. ¿Una nueva moda? Nota de prensa, 2013. En: Energy Control, Asociación Bienestar y Desarrollo [en línea] [consultado el 15/09/2015]. Disponible en http://energycontrol.org/noticias/501el-tampodka-una-nueva-moda.html

5. Dirección General del Plan Nacional sobre Drogas. Encuesta Estatal sobre Uso de Drogas en Estudiantes de Enseñanazas Secundarias (ESTUDES) 2012-2013. Madrid: Ministerio de Sanidad, Servicios Sociales e Igualdad; 2014. Disponible en www.pnsd.msc.es/ Categoria2/observa/pdf/PresentESTUDES2012 2013.pdf 